\section{Britain drops ESA project}

\section{London}

ThE UK Science and Engineering Research Council (SERC) has pulled out of a multi-million-pound European Space Agency microgravity research programme. The decision was made after a report prepared by Sir Brian Pippard, of the University of Cambridge, estimated the cost of maintaining a "useful presence in microgravity" at $£ 8$ million a year.

In a response to the report, Prospects for British participation in microgravity research, SERC chairman E.W.J. (Bill) Mitchell concluded that "there is insufficient evidence of scientific promise to justify our involvement in a major programme". Pippard, who considered the

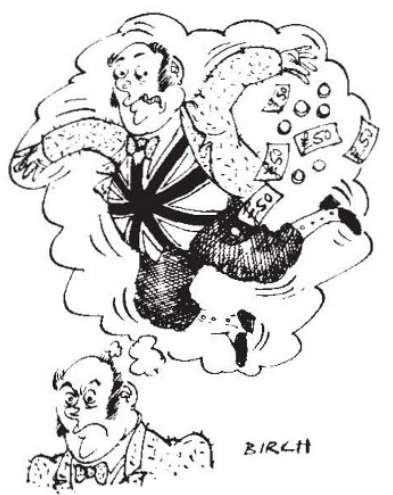

funds available to British scientists, said he could find no "strong case" for microgravity research.

Critics of SERC's decision to forgo the microgravity programme say the selection of Pippard, a physicist and material scientist, prevented an accurate appraisal of the biological importance of the mission. At least half the microgravity programme is concerned with fundamental research in biology. They say Pippard's claim that "microgravity promises no more than an inward consolidation, tidying up neglected areas of a science that is already so well delineated as to be termed classical" is flawed.

Professor Heinz Wolff, of the Institute for Bioengineering at Brunel University and chairman of the ESA Microgravity Advisory Committee, said the Pippard report misrepresented the scientists who are keen to see the programme go ahead. Wolff, who is working on the JUNO project, which will see British scientists involved in microgravity experiments on the Soviet Mir space station, said that he had already received many microgravity experiment proposals. That "would seem to contradict the assertion that interest in the UK is small", he said.

Professor Kenneth Pounds, of the University of Leicester, also regrets the SERC decision. He said the decision was based on a desire for "short-term returns" on investment in research and added that it was a lost opportunity for research into areas of biology, physics, chemistry and material science. "Other European countries and the Americans believe it is a great chance to carry out basic research. Pippard has thought about the most predictable opportunities and concluded it is not worth it. For even a modest sum we could include Britain in what could develop into a very exciting field."

Ben Webb
Royal Society suspends collaborations

\section{London}

THE Royal Society of London has announced that it is to suspend some of its collaborative agreements with Chinese government bodies.

The society says that because of the "tragic events" in China it will cut relations with the Ministry of Geology and Mineral Resources and has suspended its memorandum of understanding with the National Science Foundation of China. In a statement, the society explained: "We do not intend to make grants to British scientists to attend international scientific meetings held in China until it can be sure that such

\section{IMAGE UNAVAILABLE FOR COPYRIGHT REASONS}

A member of the Chinese Solidarity Campaign beats a traditional drum during the unveiling of a replica statue of the 'Goddess of Democracy', across the road from the Chinese Embassy in London's Portland Place.

meetings are fully international and that attendance by British scientists will not be used to imply support for the government policies".

The society will continue to help individual British and overseas scientists to "develop and maintain contact for their mutual benefit - irrespective of political considerations". The society says it will maintain its support for visits arranged by the Chinese Academy of Science, the Chinese Academy of Medical Science and the China Association for Science and Technology.
Ben Webb
- Japan's efforts beneath the ocean met with better fortune last week, when the submersible Shinkai 6500 achieved a world record depth of $6,527 \mathrm{~m}$ in the Japan Trench. The previous record was $6,170 \mathrm{~m}$ set by the Soviet vessel Mir in 1987. 